\title{
Investigating the impact of pore connectivity and dead-end pores on mineral dissolution through microfluidics
}

ELANOR HEIL, BRIAN GORMAN, JEFF SQUIER AND

\author{
ALEXIS NAVARRE-SITCHLER
}

Colorado School of Mines

Presenting Author: eheil@mines.edu

The effect of increasing percent pore network connectivity, represented through the increasing presence of dead-end pores in the pore network, on mineral dissolution rates at $\mathrm{pH} 3$ and $\mathrm{pH} 5$ was measured using microdevices made solely of anorthite with pore networks laser ablated directly into the substrate. The presence of dead-end pores creates zones where transport is dominated by diffusion in an otherwise advection dominated system. Anorthite dissolution rates based on effluent $\mathrm{Ca}^{2+}$ fluxes out of the microdevices and normalized to total surface area ranged from 2.3 to $4.3 \times 10^{-9} \mathrm{~mol} \mathrm{~m}^{-2} \mathrm{~s}^{-1}$ for $\mathrm{pH} 3$ experiments and 1.2 to $2.4 \times 10^{-9} \mathrm{~mol} \mathrm{~m}^{-2} \mathrm{~s}^{-1}$ for $\mathrm{pH} 5$ experiments and decreased with decreasing pore network connectivity (increasing percent pore volume in dead-end pores). Because dead-end pores are regions dominated by diffusive rather than advective transport, connected surface area normalized dissolution rates were calculated to remove the contribution of surface area contained in the dead-end pores. When effluent $\mathrm{Ca}^{2+}$ fluxes were normalized to connected surface area anorthite dissolution rates were uniform at higher percent pore network connectivities and at lower connectivities increased with decreasing pore network connectivity, which is attributed to increased contribution to overall effluent $\mathrm{Ca}^{2+}$ flux from the dead-end pores through diffusion. DamKöhler and Peclet numbers for a range of reaction lengths verify our experiments were reaction limited, except at dead-end pores, where diffusion dominated. These results illustrate that surface area and pore network connectivity play an important control on mineral dissolution rates especially in highly heterogeneous systems. 